\title{
Electoral Systems and Immigration*
}

\author{
Giuseppe Russo ${ }^{\dagger}$ \\ Università di Salerno, CSEF and GLO \\ Francesco Salsano \\ Università degli Studi di Milano
}

May 8, 2019

\begin{abstract}
Unexplored stylized facts on OECD countries suggest that plurality electoral systems are associated with higher openness to immigration. We propose an explanation based on a retrospective voting model where immigration hurts voters but benefits a rent-seeking policymaker who appropriates part of the income generated by immigrants. To be reappointed, the policymaker must distribute compensation. With respect to proportional systems, plurality systems make it possible to compensate only a few decisive districts and leave higher after-compensation rents, producing therefore higher immigration. In our model, non-decisive districts receive no compensation at all under both electoral systems, providing a rationale for widespread anti-immigration attitudes. Notably, our results also help to explain why governments often seem more pro-immigration than voters. Finally, our model suggests that proportional systems may incentivize the enfranchisement of immigrants with voting rights and that opposition to immigration is more territorially dispersed in plurality systems. Basic evidence supports both predictions.

Keywords: electoral systems, rent extraction, retrospective voting, immigration.

JEL codes: D72, D78, F22, H00, H40.

*We thank the Editor and two anonymous referees who helped us to improve our paper with their remarks. We are also grateful to Nicola Persico for his numerous suggestions that substantially improved our work. Finally, we thank Antonio Abatemarco, Shanker Satyanath, Thierry Verdier, Alberto Bennardo, Michel Beine, Vincenzo Carrieri, Fausto Galli, Fabio Postiglione, Francesco Magris, Annamaria Menichini, Vincenzo Pierro, Giovanni Filatrella

†Corresponding author: Università di Salerno, Dipartimento di Scienze Economiche and CSEF, via Giovanni Paolo II 132, 84084 Fisciano (Italy). email: grusso@unisa.it
\end{abstract} and Erika Uberti. 


\section{Introduction}

A broad theoretical and empirical literature, in economics and political science, has examined the effects of electoral systems since the pioneering contributions of Duverger (1954) and Buchanan and Tullock (1962). This vast body of research ranges from fiscal policy to growth, corruption, income distribution, and even to economic development. Nonetheless, the possible effect of the electoral systems on immigration flows is barely considered in the literature, although this contingency is a matter of the utmost importance. Actually, although immigration is in many ways beneficial, ${ }^{1}$ its gains are not evenly distributed and voters are concerned of labor market competition, access to welfare benefits and threats to national identity. This was tangible in the latest elections for the US presidency, where immigration has been a key issue. In the UK, concerns for immigration have been crucial for the Brexit. In the EU, immigration is now perceived as the most important issue facing the Union. ${ }^{2}$ A recent 22country survey shows that $49 \%$ of respondents agree that "there are too many immigrants in our country" and only $19 \%$ disagree. $^{3}$

On the other hand, many major corporations call for less stringent immigration rules both in the US and in the $\mathrm{EU}^{4}$. These companies include not only hi-tech firms searching for skilled workers, but also farm groups, the construction sector, maintenance industries and the food services business. Policymakers are therefore caught between a rock and a hard place, and they have to find a balance between these contrasting stances. According to the literature, governments are often more pro-migration than voters because they are responsive to corporate lobbying activities (Hanson and Spilimbergo, 2001; Fasani, 2009; Freeman, 1992; Chiswick and Hatton, 2003; Facchini and Testa, 2015). Is it possible that also electoral systems play a role in this process?

If we look at immigration inflows controlling for per-capita Gross Domestic Product (GDP), an overlooked stylized fact appears, namely, inflows into countries with plurality electoral systems are much higher than inflows into countries with proportional systems (see Figure 1 below and Figures 2, 3 in the

\footnotetext{
${ }^{1}$ Immigration not only provides workers to many industries but, in the long run, also supports pension systems by contrasting the effects of decreasing fertility rates (see Storesletten 2000; Sand and Razin 2007; Gonzalez et al., 2009).

${ }^{2}$ See European Commission. (2015). See also Mayda (2006); O’Rourke and Sinnott (2006).

${ }^{3}$ Source: Ipsos 2016 Global Views on Immigration and the Refugee Crisis. In this 22 country survey, $46 \%$ of respondents agree that "Immigration is causing my country to change in a way that I don't like" and only $22 \%$ disagree. Also, $50 \%$ agree that "immigration has placed too much pressure on public services" while $18 \%$ disagree. Finally, $43 \%$ agree that "Immigrants have made it more difficult for people of your nationality to get jobs", and $25 \%$ disagree. See also Card et al. (2012), who find that worries about preserving shared religious beliefs, traditions, and customs are three to five times more important than economic competition in shaping individual attitudes to immigration.

${ }^{4}$ For the US, see Forbes, 09-17-2013, "Where do Major US Corporations Stand in the Immigration Debate?", N. P. Flannery. For the EU, see the discussion by P. Gattaz, president of the MEDEF (National Confederation of French Employers) on "Le Monde" 09-08-2015. See also the report \# 26-2016 of Centro Studi Confindustria (Federation of Italian Employers) "Immigrants: from emergency to opportunity".
} 
Appendix $)^{5}$. This striking difference increased from 1996 to 2014. In Table 3, we show simple cross-country regressions based on OECD countries over the 1998/2014 period, which confirm that a "plurality" dummy has a significant effect on per-capita immigration inflows ${ }^{6}$. Further empirical evidence on the predictions of our model is presented in Section 4.

[FIGURE 1 HERE]

What makes these figures so different? Are plurality systems able to reduce barriers to immigration? How do these systems shape policymakers' incentives in immigration policies?

The relationship between electoral systems and immigration policy is the object of this paper. While many authors analyze the vote over immigration policies $^{7}$, the possible effect of the electoral system on the openness to immigration has been largely neglected. We study this issue through a retrospective voting model à la Persson and Tabellini (2002). The idea of accountability is the cornerstone of this model. According to Persson and Tabellini (2002), "elections discipline politicians through some sort of reputation mechanism, not because of outright enforcement". For instance, a blatantly corrupted/unfit politician would never be re-elected. More generally, since electoral promises are not credible, voters evaluate politicians ex post. Note that, in line with this simple reasoning, voters look backward, not forward: accountability is essentially retrospective. This behavior can be formally described by assuming that voters re-appoint the incumbent policymaker if and only if they are provided with a pre-determined reservation utility.

Retrospective voting has been studied extensively since the seminal work of Key (1966), and several authors over the last decades found evidence that voters reward incumbent politicians for good economic performances and punish them for bad economic performances (see Kramer, 1971; Lewis-Beck, 1988; Markus, 1988). Wolfers (2013) and, more recently, Drago et al. (2017) confirm the robustness of this finding 8 .

In our version of the Persson-Tabellini framework, a rent-seeking policymaker uses immigration to increase the fiscal base he can appropriate. In practice, as argued above, politicians benefit from immigration mainly thanks to lobbying activities. Since for our purposes it is indifferent whether rents come from tax appropriation or from lobbying, we assume for simplicity direct tax appropriation by the policymaker. The latter, however, cannot set immigration

\footnotetext{
${ }^{5}$ Source: OECD Online Statistics (2017). The charts in figure 1 show the immigration inflows for each dollar of GDP pro capite.

${ }^{6}$ The list of our countries is in Table 1. Descriptive statistics are in Table 2. Our dependent variable is the per-capita immigration inflow. Our explanatory variables include a dummy for the electoral system, standard indicators of per-capita income and economic development, controls for the demographic structure and for several institutional characteristics, such as former colonial empires and the rules that grant citizenship. In the appendix, we also perform standard robustness checks.

${ }^{7}$ See Benhabib, (1996); Dolmas and Huffman, (2004); Facchini and Mayda, (2008); Russo, (2011); Bohn and Lopez-Velasco, (2019).

${ }^{8}$ In addition, experimental evidence shows that individuals over-condition on the observed outcomes their inferences regarding the leader's effort (Petty and Weber, 2007).
} 
as he pleases. In our model, immigration damages the voters by causing congestion of public goods. To be reappointed, the policymaker must compensate his electoral base for this congestion. The net benefits available after distributing compensation depend on the electoral system. Plurality systems make it possible to compensate only a few "decisive" voters, ${ }^{9}$ and this allows to retain higher after-compensation rents for any immigration inflow. This explains why plurality systems can be more open to immigration.

Another important feature of our model is that compensation occurs either through locally provided public goods (henceforth "public goods") or through non-targetable, wide-ranging welfare programs that benefit individuals based on their personal characteristics (henceforth "transfers"). ${ }^{10}$ Therefore, we can also address the bias in public expenditures introduced by electoral systems. In line with many authors, we find that proportional systems bias spending toward extensive, non geographically-targeted transfer programs, which better fit the need to secure larger majorities. ${ }^{11}$ However, we point out that immigration may overcome this bias. The overcoming occurs because it is hard to deny transfers on the basis of nationality: immigrants with the same characteristics as the natives cannot be discriminated against forever. The leakage of transfers to nonvoting immigrants has some interesting consequences; actually, it reduces the policymaker's rent without any electoral advantage. Therefore, a policymaker who likes popularity may try to extend the voting franchise to immigrants. Note that this would be less effective in a plurality system, where only the immigrants residing in the decisive districts receive some benefits in the form of increased public goods. Thus, granting voting rights in the proportional system dominates granting voting rights in the plurality system.

This result provides us with an additional prediction, namely, proportional systems could favor voting enfranchisement. We checked whether access to voting rights for immigrants is easier under proportional representation. In the OECD, immigrants have voting rights in $74 \%$ of countries with proportional systems and in $36 \%$ of countries with plurality systems (see Table 4). The possibility of using enfranchisement to gain immigrants' vote can be considered another form of the Curley effect put forward by Glaeser and Shleifer (2005): the incumbent policymaker strategically grants voting rights to enlarge his political base.

\footnotetext{
${ }^{9}$ This mechanism is better explained in section 2.3 .

${ }^{10}$ Although there is no general agreement on this notation (Lizzeri and Persico, 2001, argue that targetable expenditures should more properly be defined as pork-barrel spending), these definitions are often adopted in the literature (see, for example, Milesi-Ferretti et al., 2002). According to Persson (2002), what matters is that some expenditures can be targeted to specific areas, while others cannot. The specific form of targeting is not important.

${ }^{11}$ See Persson, (2004) and (2002); Persson and Tabellini, (2002); Lizzeri and Persico, (2001); Milesi-Ferretti et al., (2002); Grossman and Helpman, (2009); Ticchi and Vindigni, (2009); Breunig and Busemeyer, (2012); Chang, Kayser and Rogowski, (2008); Gagliarducci, Nannicini and Naticchioni, (2011). According to Iversen and Soskice (2006), the bias of proportional systems towards transfers is reinforced by the fact that left-leaning governments are more likely to be formed under proportional rules. Jurado and Leòn (2017) show that the concentration of transfers recipients in certain regions can reduce the bias of plurality systems towards public goods.
} 
Our approach based on rent-seeking and compensation brings to light another consequence, namely, the need to compensate only decisive districts implies that the others receive no compensation at all. In this sense, there is an excess of immigration. Actually, since in both electoral systems non-decisive districts are disregarded, there will always exist an excess of immigration. This distortion is particularly serious in the plurality system, where only the voters of few decisive districts are compensated.

Summarizing, our model accounts for several stylized facts: it explains why governments tend to be more pro-immigration than voters; why plurality systems allow for more immigration; why proportional systems seem to encourage voting enfranchisement. In addition, it suggests that large shares of population are not compensated for the costs of immigration, and this could help to explain the anti-immigration sentiment in the public opinion.

Our result concerning the greater openness of the plurality system is analogous to a finding in Morelli and Negri (2017). These authors study the relationship between electoral systems and immigration through a model based on Austen-Smith (2000). In their framework, the plurality system implements the median voter's preference and the proportional system requires a coalition of two parties. Another fundamental difference from our approach is that, while in Morelli and Negri (2017) wage competition by immigrants is crucial, our model does not rely on this elusive effect. ${ }^{12}$ In addition, Morelli and Negri (2017) take the partition of resources accruing to immigrants and natives as given. As we have stressed above, the choice over the redistribution of the fiscal base made available by immigration is at the core of our contribution.

The radical differences we have outlined make Morelli and Negri (2017) highly complementary to this paper. In particular, the affinity of the result about the greater openness to immigration in the plurality system suggests that this finding is not ad hoc and can be supported by different theoretical backgrounds ${ }^{13}$. This is even more important, since an accurate empirical verification requires a long-term effort of data collection.

The paper is organized as follows: in the next section, we present our retrospective voting model; section 3 presents the results; section 4 discusses some testable implications and some empirical support for our findings; section 5 concludes. The proofs are shown in the Appendix.

\footnotetext{
${ }^{12}$ See the 30-year still unsettled debate pioneered by Card (1990) and continued by many prominent contributions, like Ottaviano and Peri, (2012); Aydemir and Borjas, (2011); Borjas (2017); Peri and Yasenov (2015); Peri and Foged (2016), to mention but a few.

${ }^{13}$ This holds even though Morelli and Negri (2017) also show that when taxation is endogenous the proportional system can be more open. In their model, this happens because the combination of extra tax base made available by immigration and higher tax rates may increase the transfer to the pivotal voter, in the case he is unemployed. Since tax rates tend to be stable over long periods, we expect that this case is uncommon.
} 


\section{The model}

In formal terms, a retrospective voting model is a game between the voters and the government. In line with Persson and Tabellini (2002), our government is made of a single, rent-seeking policymaker. The timing of the model is as follows:

1) Voters set a reservation utility $\varpi$ required to re-appoint the incumbent policymaker.

2) The policymaker decides the immigration inflow $m$ allowed into the economy.

3) The policymaker collects taxes, compensates the losses of the decisive voters $^{14}$ and retains the remaining tax base as a rent.

4) Vote is held, and the policymaker is re-appointed if the decisive voters receive at least $\varpi$.

In order to improve the intuition of the model, it is helpful to remark that, as the policymaker sets the immigration level (stage 2), immigrants spread evenly among all districts by assumption. Clustering of immigrants in specific districts can be seen as a particular case that makes things simpler for the policymaker ${ }^{15}$. We now describe the players and their utility functions.

\subsection{The voters}

Before introducing the voters' utility, it is quite useful to clarify our notation. We consider a representative democracy that assigns $C$ seats in a national parliament. $n$ voters are partitioned in different electoral constituencies. The number of constituencies varies according to the electoral system: in the proportional system, a single national constituency assigns all of the seats; in the plurality system, each costituency assigns a seat. In order to simplify the upcoming discussion, we split each electoral constituency into two equally-sized districts. In general, a voter $i$ belongs to district $j$ in constituency $k$. Since the number of constituencies differs in the two electoral systems, these indexes have different ranges, which we show below.

Proportional system: one constituency and two districts. Consequently, $i=1, \ldots n / 2 ; j=1,2 ; k=1$.

Plurality system: $C$ constituencies and $2 C$ districts. Each constituency includes $n / C$ voters, and each district $n / 2 C$ voters. Consequently, $i=1, \ldots n / 2 C$; $j=1,2 ; k=1, \ldots C$.

The voters' indirect utility includes the after-tax wage and public spending, in the form of transfers $(f)$ and local public goods $\left(g_{j k}\right)$. For the analysis it is essential to stress that transfers are allocated on the basis of individual

\footnotetext{
${ }^{14}$ We define the "decisive voters" in section 2.3 .

${ }^{15}$ In such a case, the policymaker could focus on the districts with fewer immigrants, in order to reduce the compensations he has to pay. In addition, he could exploit such heterogeneity to further increase his rents by increasing as much as possible immigration into non-decisive districts. This is another reason why plurality systems could be more open to immigration.
} 
characteristics and cannot be geographically targeted. ${ }^{16}$ On the other hand, local public goods are provided on a territorial basis, and this is why they are indexed by district $(j)$ and constituency $(k) .{ }^{17}$ $k$ :

We denote with $\omega_{i j k}$ the indirect utility of voter $i$ in district $j$, in constituency

$$
\omega_{i j k}=(1-t)+\Psi_{i} f+h\left(g_{j k}, m\right)
$$

where $(1-t)$ is the after-tax income $(t \in(0,1)), f \geq 0$ is a transfer, and $\Psi_{i}$ is an indicator function that is one if the voter is entitled to the transfer and zero otherwise. $h\left(g_{j k}, m\right)$ is a continuously three-times differentiable function that depicts the utility of the public good and a congestion effect due to immigration.

Income is normalized to unity for both natives and immigrants, thus we assume that immigration does not affect wages. This modeling choice is very important, because it makes our results independent of wage competition. Since the empirical evidence on this issue is still too controversial, we do not use it as the basis of our model (see Ottaviano and Peri, 2012; Aydemir and Borjas, 2011; Borjas 2017; Peri and Yasenov 2015; Peri and Foged 2016). For our results to hold, we only need that immigration hurts the natives' utility, and a simple congestion effect is sufficient for this purpose. Moreover, this assumption perfectly fits the widespread perception that immigration places a burden on public services reported by the recent 22-country survey cited in the introduction (see also footnote 3 ). Thus, the congestion effect also captures the xenophobic prejudices that can be important in determining attitudes to immigration (see, for instance, Card et al., 2005; O’ Rourke and Sinnott, 2006; Mayda, 2006).

We now specify the properties of $h\left(g_{j k}, m\right)$. As in Persson and Tabellini (2002), the marginal utility of the public good $g_{j k}$ is positive and decreasing; thus, $h\left(g_{j k}, m\right)$ is strictly concave in $g_{j k}$. The following derivatives describe the congestion effect:

$$
\begin{aligned}
h_{m}\left(g_{j k}, m\right) & <0 ; \\
h_{m m}\left(g_{j k}, m\right) & <0 ; \\
h_{m g}\left(g_{j k}, m\right) & <0 .
\end{aligned}
$$

Derivative (2) can be considered the marginal cost of immigration in terms of utility. It indicates that population inflows tend to jeopardize the provision

\footnotetext{
${ }^{16}$ As we argue in the next section, this crucially implies that immigrants who meet these characteristics cannot be indefinitely banned from transfers.

${ }^{17}$ For our argument, it is essential that public goods can be targeted precisely. Actually, they have to be provided to a subset of voters within a constituency: the "district" in the notation. This requires that expenditures can be addressed very precisely. This is possible for many important goods, like schools, roads or hospitals. Note that if local public goods take the form of new universities, they may increase the natives' mobility, thus reducing the district's congestion (Boeckerman and Haapanen, 2013). However, this is a very particular case, which is necessarily linked to a una tantum expansion of higher education, so we rule it out.
} 
of services such as education, public transportation, health care and so on $^{18}$. Derivative (3) assures that this marginal cost is increasing. Derivative (4) states that a marginal increase in immigration reduces the marginal utility of public $\operatorname{goods}^{19}$.

\subsubsection{Accountability}

How can voters maximize their utility in this framework? Since their wage is fixed, their utility is determined by the public expenditures they receive and on immigration. Both are under the policymaker's control. Since the latter wants to maximize his rent, he could simply maximize the tax base by letting immigrants in and then appropriating $\mathrm{it}^{20}$. This would be the worst possible outcome for the voters. However, the policymaker also wants to be re-appointed, in order to benefit from future rents. The voters are aware of this trade-off, and try to discipline him through electoral accountability. The retrospective voting model assumes that the voters coordinate on the same strategy; namely, punishing the incumbent politician for bad behavior and rewarding him for good behavior. Thus, they set a reservation utility $\varpi$, and re-appoint him if and only if he provides at least $\varpi$. This voting strategy boils down to setting the re-appointment probability $p_{i j k}^{v}$ as follows:

$$
p_{i j k}^{v}=\left\{\begin{array}{rrr}
1 & \text { if } \quad \omega_{i j k} \geq \varpi \\
0 & \text { otherwise }
\end{array}\right.
$$

where $\varpi$ is the reservation utility, and $\omega_{i j k}$ the indirect utility after the immigration is observed and public expenditures are distributed. As we are going to show in section 3.2 , at the equilibrium $\varpi$ is set according to the policymaker's incentive constraint.

\subsection{The policymaker}

The policymaker wants to maximize the utility

$$
E(U)=\gamma r+p_{v} R
$$

where $r \geq 0$ denotes the current rent he is able to extract. Rent extraction is assumed to be distortionary; thus, a share $(1-\gamma)$ of $r$ goes wasted. $R$ denotes exogenous future rents in case of re-appointment, which occurs with probability

$$
p_{v}=\left\{\begin{array}{l}
1 \text { if } \omega_{i j k} \geq \varpi \forall i \text { in the set of the decisive voters; } \\
0 \quad \text { otherwise. }
\end{array}\right.
$$

\footnotetext{
${ }^{18}$ Pure public goods are not rival, thus, for simplicity, they are omitted.

${ }^{19}$ This is a sufficient condition to assure an interior solution for the equilibrium level of immigration. The necessary condition, which is less restrictive, is

$$
h_{m g}\left(g_{j k}, m\right)<\frac{h_{m m}\left(g_{j k}, m\right) h_{g}\left(g_{j k}, m\right)}{h_{m}\left(g_{j k}, m\right)} .
$$

In other words, we only need un upper bound to $h_{m g}\left(g_{j k}, m\right)$. For ease of exposition, we prefer the more readable condition provided by (4).

${ }^{20}$ In the aggregate budget constraint (8) immigrants add to the tax base.
} 
The decisive voters are those who are necessary to win the majority of the seats under the different electoral systems. They are fully characterized in section 2.3. Future rents $R$ are the reason why the policymaker is interested in winning the election $^{21}$. Note that the policymaker controls the immigration level $(m)$, the transfer $(f)$ and the public good $\left(g_{j k}\right)$. After setting $m$ (stage 2), he allocates the fiscal revenues between $g_{j k}$ and $f$ in such a way to maximize his rent (stage $3)$.

Of course, as we argued in the introduction, rents come mainly from proimmigration lobbies. However, showing the interaction between the policymaker and the lobbies would unnecessarily complicate the model: for our purposes, we only need that the policymaker gets some benefits from immigration. Whether these benefits come from lobbying activities or tax appropriation is indifferent. Thus, we simplify our analysis and proceed by assuming tax appropriation. Remark also that, since appropriation occurs after compensation is distributed to the decisive voters, the policymaker takes into account the aggregate budget constraint, which includes expenditures for public goods, transfers, and rents:

$$
t(n+m)=g+f(n+m) \sigma+r .
$$

The left-hand side of the budget constraint is the fiscal base. On the righthand side, $g=\sum_{j=1}^{2} \sum_{k=1}^{C} g_{j k}$ is the aggregate expenditure for public goods, $r$ is the rent, and $f(n+m) \sigma$ is the aggregate expenditure for transfers, where $\sigma \in[0,1]$ denotes the share of natives and immigrants entitled to transfers. Since $\sigma$ is the same for both groups, we are assuming that immigrants are equivalent to natives. This assumption is by no means necessary, but it remarkably simplifies our exposition ${ }^{22}$. In section 3, we show that the policymaker sets $\sigma=1 / 2$.

Our next step is to characterize the difference between the electoral systems.

\subsection{Electoral systems}

In our model of representative democracy, an incumbent policymaker runs against an identical opponent. $C$ seats can be assigned either under plurality or proportional representation. Following Persson and Tabellini (2002), we assume for simplicity that $C / 2$ seats are sufficient to win the election. We also assume that one half of the votes is sufficient to win in each constituency. In order to simplify the notation, we split each constituency into two equally-sized

\footnotetext{
${ }^{21} R$ can be interpreted as the expected present value of holding office. For simplicity, here $R$ is exogenous. See Ferejohn (1986) and especially Persson, Roland and Tabellini, (1997) for models where future benefits are endogenous.

${ }^{22}$ Since what matters for our purposes is only that some leakage of transfers toward immigrants is inevitable, we keep the model as simple as possible. Actually, though it is usual to restrain transfers to immigrants (for instance with minimum residence requirements), those who have the same carachteristics as the natives cannot be discriminated against forever. For this reason, large inflows of poor immigrants raise concerns on their fiscal burden and have generated a vast literature. In Milton Friedman's words, "It's just obvious that you can't have free immigration and a welfare state." For related research, see Facchini et al., 2004; Kaushal, 2005; Razin et al., 2002; Razin et al., 2011; Nannestad, 2007.
} 
districts, so that the support of one district is sufficient to win the constituency's seat.

In the plurality system, each of the $C$ constituencies assigns a seat. As the winner needs $C / 2$ seats, he has to secure $C / 2$ districts. With some abuse of notation, we define these districts as "decisive districts" and their voters as "decisive voters."

Consider now a proportional system, which can be depicted as a single national constituency where a single decisive district assigns $C / 2$ seats. Note that this district includes $n / 2$ decisive voters. In a plurality system, each district includes $n / 2 C$ voters. Because the winning candidate needs the support of $C / 2$ districts, there are $n / 4$ decisive voters. This well-known difference is crucial for our results.

We show the solution of the model in the next section.

\section{Solving the retrospective voting model}

Since the model is solved backwards, recalling the timing can be useful. Stage 1): the voters set their reservation utility; stage 2): the policymaker chooses the immigration level; stage 3): the policymaker distributes the electoral compensations and retains his rent; stage 4): elections are held.

Before solving the model, some preliminary considerations will b helpful to simplify our exposition. First, we remark that, in equilibrium, the policymaker compensates decisive voters either through public goods or through transfers (he chooses the tool with the lower marginal cost) ${ }^{23}$. Then, we clarify that, when the electoral compensations are distributed through transfers, they must go to one half of the voters. This makes it possible to simplify the aggregate budget constraint (8) by setting $\sigma=1 / 2$, as we summarize in the following lemma:

Lemma 1 In any electoral system, either transfers are distributed to 1/2 of the voters, or they are not used at all. Thus, either $f>0$ and $\sigma=1 / 2$ or $f=0$.

Proof. See the Appendix.

To intuitively understand the lemma, consider a policymaker who satisfies all voters with transfers by setting $\sigma=1$. In such a case, he can increase his rent by reducing $\sigma$ to $1 / 2$, while still being re-appointed. However, if he reduces $\sigma$ below $1 / 2$, he will not be re-appointed.

Restraining transfers to one half of the voters is possible by properly choosing the personal characteristics $\Psi_{i}{ }^{24}$. Thus, the aggregate budget constraint (8) becomes

$$
t(n+m)=g+f\left(\frac{n+m}{2}\right)+r .
$$

\footnotetext{
${ }^{23}$ See the proof of proposition 2 in the appendix.

${ }^{24}$ In practice, different criteria for transfers benefit different individuals. For instance, the policymaker can allocate family aid depending on the number of children or on their age; the same holds for rent subsidies and scholarships. Criteria for entitlement to unemployment benefits are another example.
} 
We can now proceed in the solution of the model. Suppose for the moment that the policymaker is re-appointed in stage 4 and let us focus on stage $3^{25}$. In this stage, immigration is fixed at the optimal level set in stage 2). The policymaker only has to collect the tax revenues, compensate decisive voters, and retain his rent. While distributing compensation, he uses the cheapest between public goods and transfers. In the next section, we specify the conditions under which he chooses the former or the latter.

\subsection{The optimal immigration and the choice between pub- lic goods and transfers}

Immigration is set in the second stage at a level that maximizes the rent the policymaker collects in the third stage. We denote with $\bar{m}$ the arbitrarily high stock of potential immigrants. Maximization proceeds by allowing entry until the marginal benefit on the tax base equals the marginal cost of compensation. Because voters' compensation may occur either through transfers or through public goods, in each electoral system there are two marginal costs of compensation. As a consequence, there exist two immigration levels for which the marginal benefit equals the marginal cost of compensation. The policymaker chooses the method that leaves him the highest rent ${ }^{26}$. According to our results, plurality systems bias his choice towards public goods, and proportional systems towards transfers. However, we also prove that immigration can overcome both biases. We state this result in the next proposition.

Proposition 2 (electoral systems and the bias in compensations). Plurality systems bias compensations towards public goods, and proportional systems towards transfers. However, immigration can overcome these biases and make the policymaker use either public goods or transfers in both systems.

Proof. See the appendix

The bias introduced by the electoral system is well-known in the literature (Persson, 2002 and 2004; Persson and Tabellini, 2002; Milesi-Ferretti et al., 2002), and appears since public goods can easily be targeted on the decisive districts required to win in plurality systems, while transfers are more fit to benefit the larger majority required by proportional systems.

We add to the literature by proving that immigration can overcome both these biases. The bias towards public goods can be overcome if too much congestion makes these goods (marginally) useless. The bias towards transfers can be overcome if their leakage to immigrants reduces significantly the policymaker's rent.

By assessing the marginal cost of compensation under the different electoral systems, we prove that plurality systems produce (weakly) higher immigration. This leads us to the next proposition:

\footnotetext{
${ }^{25}$ As we are going to see, re-election always happens in equilibrium because the voters set their reservation utility according to the policymaker's incentive constraint. As a consequence, he has no incentive to deviate and provides the decisive voters with the required utility.

${ }^{26}$ This is explained in the proof of proposition 2 .
} 
Proposition 3 (electoral systems and immigration): in equilibrium, the immigration level is weakly greater in plurality electoral systems.

Proof. See the appendix.

This proposition is the most important result of our model. It holds because, in general, plurality systems enable the policymaker to compensate only $C / 2$ districts -namely, $n / 4$ voters- while disregarding the others. This can normally be done with public goods, and increases the rent made available by immigration. On the other hand, proportional systems make it impossible to focus on few decisive districs, and leave lower rents. In such a case, transfers are more fit to satisfy a larger majority and immigration is lower.

The two systems produce the same immigration level only when both use transfers. In such a case, the electoral compensations go to $1 / 2$ of the voters under any electoral system, and the marginal compensation cost is the same. Instead, when both systems use public goods, immigration is still higher under plurality rule, where only $n / 4$ voters are decisive and the marginal compensation cost is lower.

Let us now summarize how our findings relate to the literature. We confirm two main results: 1) plurality systems tend to convey locally provided public goods towards the decisive districts and reduce transfers; 2 ) the benefits of public spending are more evenly distributed under proportional systems. However, we also add some novel results: 1) plurality systems can reduce barriers to immigration; 2) immigration may overcome the bias of proportional systems toward transfers and the bias of plurality systems towards public goods.

\subsection{Incentive constraint and equilibrium rent}

In the first stage, the voters set the highest reservation utility $\varpi$ compatible with the policymaker's incentive constraint, which we are going to construct. From equation (6) we know that the policymaker's utility in case of re-appointment is

$$
U_{E}=\gamma r+R,
$$

(where $r$ is the rent, $R>0$ is the value of re-election and $\gamma \in(0,1)$ is the distortion due to rent appropriation). Alternatively, he may choose not to be re-appointed, and appropriate the whole tax base, which gives utility

$$
U_{N E}=\gamma t\left(n+m^{*}\right),
$$

where $m^{*}$ is the equilibrium immigration level under the different electoral systems. Solving the incentive compatibility condition $\left(U_{E} \geq U_{N E}\right)$ for $r$ gives the equilibrium rent

$$
r^{*}=t\left(n+m^{*}\right)-\frac{R}{\gamma} .
$$

From equation (12) we obtain $\frac{\partial r^{*}}{\partial m^{*}}>0$. By proposition 3, it follows that the policymaker's rent in the plurality system is greater or equal to his rent in the proportional system. 
From equation (12) it also follows

$$
t\left(n+m^{*}\right)=r^{*}+\frac{R}{\gamma} .
$$

The left-hand side of equation (13) is the tax base in equilibrium. The righthand side shows that the resources left to the voters once the incentive constraint is satisfied are the same -namely, $R / \gamma$ - under both electoral systems. In other words, all the tax base exceeding $R / \gamma$ flows into rents. In the spirit of the styilized facts we have presented in the introduction, this means that we end up with a policy that concentrates the benefits of immigration on the policymaker and on the group of pro-immigration lobbies supporting him. On the other hand, the costs of immigration are spread over the reamining population: decisive voters are kept indifferent to immigration, but non-decisive voters are definitely hurt. We develop this analysis in the following section.

\subsection{Voters' equilibrium utility}

In our model, voters can be either decisive or non-decisive. The latter are not compensated at all for immigration, thus computing their utility is easier. In our simplified framework, they do not receive neither public goods nor transfers under both electoral systems. As a consequence, in equilibrium, their utility is only determined by the immigration level:

$$
\tilde{\omega}_{N D}=(1-t)+h\left(0, m^{*}\right),
$$

where $m^{*}$ is the equilibrium immigration under the different electoral systems ${ }^{27}$. By proposition 3, we know that $m^{*}$ in proportional systems is never larger than in plurality systems. Thus, non-decisive voters are (weakly) better off in proportional systems. Remarkably, non-decisive voters are $1 / 2$ of the voters under proportional representation and $3 / 4$ of the voters under plurality rule. These results confirm that proportional systems tend to protect a larger share of voters, and that plurality electoral systems might intensify territorial imbalances. However, the existence of large shares of neglected voters under both electoral systems provides a solid rationale for the formation of extensive anti-immigration sentiment. We elaborate on this point in section 4, where we present some empirical support for our findings. For the moment, we turn to the decisive voters' equilibrium utility, which is computed as follows: we substitute the optimal immigration inflow and the incentive-compatible rent (12) into the aggregate budget constraint (9). Then, we solve (9) with respect to $g$ and $f\left(n+m^{*}\right) / 2$

\footnotetext{
${ }^{27} h\left(0, m^{*}\right)$ does not imply that non-decisive voters do not receive public goods. Rather, it means that these voters do not receive any compensation for the inflow of immigrants. In other words, pre-existing public goods get congested, but the policymaker does not increase their baseline level, which we conventionally label "0". In an older version of this model (Russo and Salsano, 2012) we show that we can easily obtain a positive level of public goods for non-decisive voters. However, this would only complicate the algebra, so we prefer keeping the simpler notation $h\left(0, m^{*}\right)$.
} 
respectively, and we obtain the aggregate amount of public goods $(g)$ and transfers $\left(f\left(n+m^{*}\right) / 2\right)$ used for the electoral compensations. Finally, we divide these aggregates by the number of decisive districts (voters) and find the individual compensations to be plugged into utility (1).

Since the effect of immigration can overcome the bias towards public goods in plurality systems and the bias towards transfers in proportional systems, the analysis of the decisive voters' utility is less straightforward, because we have to take into account different cases. By proposition 2, we know that there are three possibilities:

a) Compensations through public goods in the plurality system and through transfers in the proportional system;

b) Compensations through public goods in both systems;

c) Compensations through transfers in both systems.

We refer to a) as the "standard" case, and to b), c) as the "particular" cases. In order to avoid ambiguities, in what follows $m^{*}$ denotes the equilibrium immigration in the plurality system and $m^{* *}$ denotes the equilibrium immigration in the proportional system. By proposition 3, we know that $m^{*} \geq m^{* *}$.

In case a), the decisive voters' utility is

$$
\begin{array}{lc}
\varpi_{p l(a)}=(1-t)+h\left(\frac{2 R}{\gamma C} ; m^{*}\right) & (\text { plurality }), \\
\varpi_{p r(a)}=(1-t)+h\left(0, m^{* *}\right)+\frac{R}{\gamma}\left(\frac{2}{n+m^{* *}}\right) & \text { (proportional). }
\end{array}
$$

In case b), the decisive voters' utility is

$$
\begin{array}{ll}
\varpi_{p l(b)}=(1-t)+h\left(\frac{2 R}{\gamma C} ; m^{*}\right) & \text { (plurality), } \\
\varpi_{p l(b)}=(1-t)+h\left(\frac{R}{\gamma C} ; m^{* *}\right) & \text { (proportional). }
\end{array}
$$

In case c), the decisive voters' utility is the same under both systems, namely,

$$
\varpi_{(c)}=(1-t)+h\left(0, m^{*}\right)+\frac{R}{\gamma}\left(\frac{2}{n+m^{*}}\right) .
$$

We cannot compare the decisive voters' utility in case a) because the arguments of equations (15) and (16) are different, and the function $h\left(g_{j k}, m\right)$ is a generic one ${ }^{28}$. The same holds for equations (17) and (18) in case b). In case c), instead, both electoral systems generate the same level of immigration, and compensations occur through transfers. As a consequence they are equivalent and generate the same utility.

In the next section, we try to compare the decisive voters' utility in case a) and b) through some numerical examples.

\footnotetext{
${ }^{28}$ On comparing equation (17) and equation (18), we see that the former includes more public goods and more immigration (i.e., higher congestion), and the latter includes less public goods but also less immigration (i.e., lower congestion).
} 


\subsection{Numerical analysis of the decisive voters' utility}

Here, we try a numerical analysis of the decisive voters' utility under the different electoral systems. Such an exercise is hardly general; nonetheless, it delivers some interesting insights. We use the following function form for $h\left(g_{j k}, m\right)$ :

$$
h\left(g_{j k}, m\right)=\left[x g_{j k}^{a}-(1-x) m^{b}\right]^{z},
$$

where $x, z \in(0,1) ; a \geq 1 ; b \geq a$. Under these restrictions, equation (20) easily satisfies assumptions (2), (3) and (4). We proceed as follows: first, we assign values to $x, z, a, b$. Then, we find the equilibrium immigration that equalizes the marginal benefit $t$ to the marginal compensation cost in cases a) and b), given by equations (24) and (25) in the appendix. Finally, we put the values of $m$ so obtained into the equilibrium utilities (15) and (16) (case a); (17) and (18) (case b).

Let us start from case (a); namely, compensations occur through transfers in the proportional system and through public goods in the plurality system. In order to understand our results, note that, in this case, proportional representation drastically reduces immigration. ${ }^{29}$ As a consequence, immigration scarcely affects the decisive voters' utility (16). To realize this outcome, just consider that in equation (16) the term $\frac{R}{\gamma}\left(\frac{2}{n+m^{* *}}\right)$ is grosso modo constant to $\frac{R}{\gamma}\left(\frac{2}{n}\right)$, since $m^{* *}$ is very low relative to the population $n$. By the same reason, the term $h\left(0, m^{* *}\right)$ is also grosso modo constant: the baseline level of $g_{i k}$ does not depend on the immigration level, and $m^{* *}$ is low. ${ }^{30}$ Therefore, in equilibrium, utility (16) is little reduced by immigration.

Consider now utility (15): the equilibrium level of public goods is quite higher than in the proportional system, but so is for $m$. Since $b \geq a$, the increase in congestion quickly offsets the utility of the public good, whose level is fixed at $\frac{2 R}{\gamma C}$. As a consequence, the decisive voters are better off in the plurality system only at low-immigration equilibria. ${ }^{31}$

For what concerns case (b) (both systems compensate through public goods), first we find that the proportional system generates more immigration than in

\footnotetext{
${ }^{29}$ This can be understood on observing the marginal compensation costs (24) and (25) in the appendix. In equation $(24)$, the individual compensation through public goods $\frac{-h_{m}\left(g_{j k}, m\right)}{h_{g}\left(g_{j k}, m\right)}$ is rescaled by $\left(\frac{C}{2}\right)$ districts. In equation (25), the individual compensation through transfers $-h_{m}\left(g_{j k}, m\right)$ is rescaled by $\left(\frac{n+m^{* *}}{2}\right)$ voters. Since there are more voters than districts, the marginal cost of compensation grows quickly and, in equilibrium, generates lower immigration levels.

${ }^{30}$ Note that for simplicity we have fixed at zero the baseline level of public goods (see footnote 27). Since of course there always exists some positive amount of public goods, in our numerical examples we assign $g_{j k}$ a positive value.

${ }^{31}$ For instance, if we set $x=0.7 ; a=1 ; b=2 ; z=0.9 ; c=100 ; n=900 ;(2 R / \gamma)=5000$; and the baseline value $g_{j k}=14$ in the proportional system, the decisive voters are indifferent between the two systems at $m^{*}=7.77$ and $m^{* *}=1.75$ respectively. When $m^{* *}>7.77$, the decisive voters in the plurality system are worse off even though they receive more public goods. Note also that the equilibrium immigration is four times higher in the plurality system. Such large differences emerge in all our numerical examples.
} 
case (a). This is as expected, since the marginal cost of compensation in the proportional system is now lower. However, the decisive voters' utility still behaves as in case (a): at low-immigration equilibria, decisive voters are better off in the plurality system; then, as immigration grows, the increase in congestion offsets the utility of the public good. The only difference is that now the level of immigration that makes decisive voters better off in the the proportional system is higher. ${ }^{32}$

An interesting question is whether these outcomes provide insights on the endogenous demand for a change in electoral rules when a country faces an expected inflow of immigrants ${ }^{33}$. In a referendum, the majority would clearly support the proportional system, which provides compensation to half the voters. Under representative democracy, instead, the policymaker prefers the plurality system, which provides him the highest rent. At low equilibrium immigration, the decisive voters and the policymaker agree to support the plurality system. However, as immigration increases, the former would benefit from a change of electoral system, while the latter does not. In the absence of a referendum, the policymaker continues to accumulate rents, while the decisive voters reduce their equilibrium utility. Note also that, though proportional systems reduce immigration, decisive voters are anyway worse off as immigration increases. In other words, more immigration reduces the decisive voters' utility under both electoral systems. This may also contribute to explain the worldwide opposition to immigration we have briefly documented in the introduction.

\section{Empirical evidence}

In this section, we present some empirical evidence in support of our model. Unfortunately, our data do not allow us to go beyond some basic correlations, and we do hope to develop a rigorous causal approach in future research. However, our model delivers some testable predictions, which we try to investigate at the best of our possibilities. The main testable implications are the following: 1) plurality systems should be more open to immigration; 2) opposition to immigration should be more variable at the territorial level in the plurality system; 3) the incentive to grant voting rights to immigrants could be stronger in the proportional system. In what follows, we present introductory evidence in favor of these predictions. ${ }^{34}$

\footnotetext{
${ }^{32}$ If we use the same parameters as in the previous footnote, the equilibrium immigration in the proportional system jumps from 1.7 units to 3.885 units. At this level of immigration, the decisive voters utility is still higher under the plurality system, while in the previous exercise equality occurred roughly at $m^{* *}=1.75$.

${ }^{33}$ We acknowledge an anonymous reviewer for this suggestion.

${ }^{34}$ In principle, there are other testable implications, coming from the possibility that immigration overcomes the bias imposed by the electoral system on public expenditures. According to proposition 2, there exists a cutoff level of immigration above which the policymaker uses transfers in the plurality system or, alternatively, public goods in the proportional system. Such a switch in public spending should be observable after, for instance, a sudden increase in immigration. Unfortunately, it is not easy to know the value of the cutoff, which should also be country-specific. Analyzing the effects of unexpected and large inflows of immigrants
} 


\subsection{Openness to immigration}

In order to test prediction 1), we estimate a simple cross-country regression. We use data on OECD countries (listed in Table 1) over the 1996/2014 period. The database includes economic, institutional and demographic variables. Economic variables are per-capita Purchasing Power Parity (PPP) adjusted real GDP, tax revenues in terms of GDP. Per-capita GDP proxies for wage differentials. Tax revenues over GDP account for the weight of the state in the economy, which, in turn, is a proxy of business freedom.

Institutional variables come from the World Bank's DPI database (Keefer, 2006). Electoral systems are denoted by a dummy, which is 1 if representatives are elected with a winner-takes-all/first-past-the-post rule, and zero if the electoral system is proportional. ${ }^{35}$ We also include dummies for EU membership and for the presence of former colonial empires, because the Schengen Treaty could foster within-EU migration and former colonial empires may ease mobility from member countries.

Demographic variables include the log of the total population, the percentage of working-age population, and the percentage of elderly ${ }^{36}$. According to Persson and Tabellini (2003, 2004), total population is an important proxy of development: highly populated countries are usually less developed and less attractive to immigrants. Working-age population is a measure of labor supply and indicates potential labor market competition. Finally, the percentage of elderly is important because immigration could support retirement schemes and provide domestic care services.

The measure of immigration is the $1996 / 2014$ per-capita average inflow of immigrants in OECD countries ${ }^{37}$. We estimate a pooled cross-country regression of the form

$$
m_{i}=c+\eta z_{i}+\alpha x_{i}+\beta s_{i}+u_{i}
$$

where $m_{i}$ is the measure of immigration in country $i .^{38} \quad z_{i}$ is the "plurality" dummy and $x_{i}$ includes the economic and demographic variables. $s_{i}$ includes the

-as for instance in Friebel et al., (2017)- looks promising, but that would need 1) an estimate of the cutoff levels; 2) a series of immigrations shocks that cause a non-marginal increase of the population inflow at the national level; 3) a collection of such shocks for countries with different electoral systems. We hope to explore this issue in future research.

${ }^{35}$ Note that many countries adopt a mix of the two systems. For instance, some seats may be allocated on a proportional basis in order to preserve representation. We take this feature into account by exploiting the "house system" dummy of the DPI database, which is coded 1 when the majority of seats is elected under plurality rule. When this dummy is 1 , we classify a country as under plurality rule. Australia, Italy, Hungary, and Korea are included in the plurality systems. Greece, Germany, and Spain are included in the proportional systems.

${ }^{36}$ Source: OECD Online Statistics (2017). Working-age population is aged 20-64, and the elderly are aged 65 and older.

${ }^{37}$ Source: OECD Online Statistics (2017). For our purposes, immigration flows are better than stocks because flows reduce the potential bias due to historical reasons, such as the former presence of colonial empires. Table 2 shows the cross-sectional 1996/2008 average, the standard deviation, the minimum and the maximum for each variable of the sample.

${ }^{38}$ We do not use a panel because electoral systems are in practice constant over time, and their effect is captured by the country effects. In other words, the time dimension is not useful in this case. 
dummies indicating EU membership and former colonial empires. $c$ and $u_{i}$ are the constant term and the error term, respectively.

The economic variables include the PPP adjusted GDP per-capita and the tax revenues in terms of GDP. They are labeled gdp_per_head, tax, and openness, respectively. The demographic variables (log of total population, percentage of working-age population, percentage of the elderly) are labeled pop1, pop2, and pop3. The dummies for plurality electoral systems, EU membership and colonial empires are labeled plurality, EU, and empire.

The results of the regressions are visible in Table 3 in the appendix ${ }^{39}$. The coefficient on "plurality" is positive and statistically significant at the $1 \%$ level. GDP and total population are significant at the $1 \%$ level with the expected sign (positive and negative, respectively ${ }^{40}$ ). The percentage of the elderly is $1 \%$ significant with a somewhat unexpected negative sign. However, although in principle immigration benefits the older population by sustaining the welfare system and by providing domestic care workers, it is well-known that the elderly show more pronounced anti-immigration attitudes (Card et al., 2005; O' Rourke and Sinnott, 2006; Mayda, 2006). The dummy for the presence of former colonial empires is also $1 \%$ significant, with the expected positive sign, while the EU membership does not have any effect. The negative and $1 \%$ significant effect of taxes suggests that high taxation may discourage immigration, even though the magnitude of this effect looks negligible. Finally, the highly significant and positive effect of working-age population (рор2) is in line with the findings by Ottaviano and Peri (2012), who challenge the idea that natives and immigrants are substitutes. Some robustness checks of these estimates are reported in the appendix, and show that our results are stable.

To summarize, the available data indicate that the possibility of a relationship between electoral systems and immigration initially shown in Figure 1 cannot be easily discarded. Now we present further results about the testable implications of our model.

\subsubsection{The territorial variance of anti-immigration attitude}

According to testable implication 2), opposition to immigration should be more variable at the territorial level in the plurality system. This prediction requires some explanations. If we consider a proportional system as a single, nation-wide constituency, the half of the country that includes the decisive voters should be indifferent to immigration. On the other hand, in a plurality system, attitudes to immigration should change swiftly among compensated and non-compensated districts within the different constituencies. Thus, opposition to immigration should be more territorially dispersed within plurality systems.

To check prediction 2), we have used both World Value Survey (WVS) and

\footnotetext{
${ }^{39}$ Columns 1 and 2 report the estimated coefficients and the p-values, respectively. Columns 3 and 4 report the estimated coefficients and the p-values when non-significant variables are excluded.

${ }^{40}$ Recall from section 2.1 that highly populated countries are usually less developed (Persson and Tabellini, 2003, 2004).
} 
European Social Survey (ESS) data for the period 2000-14 and 2006-12 respectively. ${ }^{41}$. The bar graph in Figure 5 (see the appendix) shows that the variance of anti-immigration attitude is higher in plurality systems by $46 \%$ (WVS) and by $294 \%$ (ESS). ${ }^{42}$ This finding is in line with our prediction. However, since this variance may depend on factors other than the electoral systems, further checks would be useful. Hence, we control its correlation with a set of other economic and political variables. First, we run a regression on the following variables: per capita GDP, the Gini index ${ }^{43}$, the plurality dummy and a dummy indicating the presence of xenophobic/nationalist parties in the Parliament ${ }^{44}$. Since we have less than 30 observations, this exercise has little statistical meaning, but nonetheless it gives some insights.

We use GDP as a standard control, even though there are no particular reasons why it should affect the variance of the opposition to immigration. The Gini index is used because more unequal countries could display more difformity in the attitude towards immigration (we furhter develop this point in the next regression). The dummy for xenophobic parties proxies for the recent boom of anti-immigration parties. Results are shown in Table 6 (WVS data) and Table 7 (ESS data): only the plurality dummy is $5 \%$ significant in both regressions with the expected positive sign.

Indicators of territorial inhomogeneity offer a possible alternative as determinants of the territorial variance of the attitude towards immigration. Actually, more unequal regions should display higher variability in this attitude: for instance, immigration could be good for top-income earners and bad for lowincome earners. Thus, a higher difference between top incomes and low incomes could generate a higher difference in the attitude towards immigration. The coefficient of variation of regional disposable income is a commonly used measure of income dispersion ${ }^{45}$.

We have run another regression (see Table 8) where both the 2014 coefficient of variation and the plurality dummy are $10 \%$ significant with the expected positive sign ${ }^{46}$. Of course, this is far from being an empirical confirmation, but, once again, our findings do not contradict the predictions of our model.

\footnotetext{
${ }^{41}$ Both WVS and ESS report regional identifiers of the respondents. Question V39 of 20002014 WVS asks the respondent whether he or she "would not like to have as neighbors: immigrants/foreign workers" Yes/no. Question B34 CARD 20 of the ESS (in several waves) asks "Is [country] made a worse or a better place to live by people coming to live here from other countries?" (Worse $=0$; better $=10$ ). Since the answer to the WVS question is dichtomous, in order to have comparable data we have transformed the answer to the ESS in a dichotomous variable as well. We have considered all answers from 0 to 3 as expressing opposition to immigration. Then we compute the variance of the measure using the standard formula for a dichotomous variable.

${ }^{42}$ In Table 5 (appendix) we report the variance for each country.

${ }^{43}$ The sources of these data are respectively the World Bank database: World Development Indicators (https://datacatalog.worldbank.org/dataset/world-development-indicators) and the database of the Federal Reserve of Saint Louis: FRED (https : //fred.stlouisfed.org/).

${ }^{44}$ The source of these data is the Political Handbook of the World (2014) and the database of A. Banks (https://www.cntsdata.com/). A summary of these data can also be found on DPI 2012.

${ }^{45}$ Source: OECD Regions at a Glance 2016 - (C) OECD 2016 p.25

${ }^{46}$ We show only the regression on ESS data because for the ESS we have only 9 observations.
} 


\subsection{Voting enfranchisement}

In order to understand why the incentive to grant voting rights to immigrants could be able under proportional representation, we need a simple addition to our model. Notice first that, in a proportional system, the policymaker is unable to ban immigrants from transfers. This fact has some interesting consequences if we note that politicians like popularity. In our model, the policymaker is only concerned about the decisive voters because gaining further popularity would reduce his rent. However, suppose that in the fourth stage -after retaining his rent but before the elections- he can grant voting rights to immigrants. In a plurality system, he could at most win the immigrants in the decisive districts $\left(0.25 m^{*}\right)$, who share the increased public goods. The remaining $75 \%$ are not supposed to support him, thus, should he grant voting rights, his popularity could even decrease. In a proportional system, instead, $m^{* *} / 2$ immigrants are directly benefited by transfers. In addition, the simplifying assumption that immigrants are like the natives looks too restrictive in this respect: since they are poorer, they are more likely to receive transfers. This could easily turn into a consensus larger that $1 / 2$. Thus, granting voting rights in the proportional system dominates granting voting rights in a plurality system. We try a rough check of this prediction through a survey of the existing national regulations. Typically, in OECD countries voting is allowed in municipal elections after 3/5 years of residence ${ }^{47}$. Immigrants can vote in 17 countries out of 23 with proportional systems (74\%) and in 4 countries out of 11 with plurality systems $(36 \%)$. Although we do not claim that this descriptive evidence is sufficient to confirm our conjecture, at least it does not contradict our predictions and is in line with the Glaeser and Shleifer's (2005) Curley effect.

\section{Conclusions}

This paper suggests that electoral systems matter not only in determining the size and the composition of government spending, but also in determining barriers and popular attitudes to immigration. To some extent, electoral systems seem even able to influence the voting enfranchisement of the immigrants. All these findings add to the literature.

Overall, our model is consistent with several stylized facts: 1) the governments seem generally more pro-immigration than voters; 2) for a given GDP per head, immigration to countries with plurality systems is twice as much immigration to countries with proportional systems; 3) the extension of voting rights to immigrants is more common in countries with proportional systems; 4) the territorial variance of anti-immigration attitudes is higher in plurality systems. We hope to develop future research to find causal evidence along the lines sketched in section 4 .

\footnotetext{
${ }^{47}$ The type of election and the requirements necessary for voting are listed in Table 4 in the appendix.
} 
For the moment, our findings also draw the attention on the role of nondecisive voters, who are disregarded by the policymaker: These voters are $1 / 2$ of the population in proportional systems and $3 / 4$ of the population in plurality systems. They can suffer losses due to immigration, but do not receive any compensation. Thus, the incentives created by the electoral systems can contribute to explain the pervasive opposition to immigration. This is all the more so under plurality rules, that can exacerbate the territorial impact of immigration. 


\section{References}

[1] Alesina A., Baqir R., Easterly W., (1999), Public Goods And Ethnic Divisions, The Quarterly Journal of Economics,114(4),1243-1284.

[2] Alesina A., Spolaore E. (2003), The Size of Nations, The MIT Press: Cambridge (Mass.).

[3] Aydemir A., Borjas G. J., (2011), Attenuation Bias in Measuring the Wage Impact of Immigration, Journal of Labor Economics vol. 29(1), 69-113.

[4] Benhabib J., (1996) On the Political Economy of Immigration, European Economic Review 40, 1737-1743.

[5] Bertocchi G., Strozzi C., (2010), The Evolution of Citizenship: Economic and Institutional Determinants, Journal of Law and Economics 53(1), 95136 .

[6] Bertocchi G. Strozzi C, (2008), International Migration and the Role of Institutions, Public Choice, Springer, 137(1), 81-102.

[7] Boeckerman P., Haapanen M. (2013), The Effect of Polytechnic Reform on Migration, Journal of Population Economics 26, 593-617.

[8] Bohn H., Lopez-Velasco A. R. (2019), Immigration and Demographics: Can High Immigrant Fertility Explain Voter Support for Immigration?, Macroeconomic Dynamics 23(5), 1815-1837.

[9] Borjas G. (2017), The Wage Impact of the Marielitos: a Reappraisal, Industrial and Labor Relations Review 70(5), 1077-1110.

[10] Breunig C., Busemeyer M. R., (2012), Fiscal Austerity and the Tradeoff Between Public Investment and Social Spending, Journal of European Public Policy, 19(6), 921-938.

[11] Buchanan J. M., Tullock G. (1962), The Calculus of Consent: Logical Foundations of Constitutional Democracy, University of Michigan Press.

[12] Card D., (1990), The Impact of the Mariel Boatlift on the Miami Labor Market, Industrial and Labor Relations Review 43(2), 245-257.

[13] Card D., Dustmann C., Preston I. (2005), Understanding Attitudes to Immigration: the Migration and Minority Module of the First European Social Survey, CREAM wp no 03/05.

[14] Card D., Dustmann C., Preston I., (2012), Immigration, Wages and Compositional Amenities, Journal of the European Economic Association 10(1), 78-119.

[15] Chang E. C., Kayser M. A., Rogowski R., (2008), Electoral Systems and Real Prices: Panel Evidence for the OECD Countries, 1970-2000, British Journal of Political Science 38(4), 739-751. 
[16] Chiswick B., Hatton T. (2003), International migration and the integration of labor markets, in Bordo M., Taylor A., Williamson J. (Eds.), Globalization in Historical Perspective, Chapter 3, 65-119, University of Chicago Press.

[17] Dolmas J., Huffman G.W. (2004), On the Political Economy of Immigration and Income Redistribution, International Economic Review 45(4), 11291168.

[18] Drago F., Galbiati R., Sobbrio F., (2017), The Political Cost of Being Soft on Crime: Evidence from a Natural Experiment. CEPR discussion paper 12097.

[19] Duverger M. (1954), Political Parties: Their Organization and Activity in the Modern State, Wiley, New York.

[20] European Commission (2015), Standard Eurobarometer 83: Public Opinion in the European Union. Available at: http://ec.europa.eu/commfrontoffice/publicopinion/archives/eb/eb83/eb83_en.htm

[21] Facchini G., Razin A., Willmann .G. (2004), Welfare Leakage and Immigration Policy, CESifo Economic Studies 50(4), 627-645.

[22] Facchini G., Testa C. (2015), The Rethoric of Closed Borders: Quotas, Lax Enforcement and Illegal Immigration, CES-IFO Economic Studies 61, 673-700.

[23] Fasani F. (2009), Deporting Undocumented Immigrants: The Role of Labor Demand Shocks, mimeo, University College London.

[24] Ferejohn J., (1986), Incumbent Performance and Electoral Control, Public Choice 50, 5-26.

[25] Foged M., Peri G. (2016), Immigrants' Effect on Native Workers: New Analysis on Longitudinal Data, American Economic Journal: Applied Economics 8(2), 1-34.

[26] Freeman G., (1992), Migration Policy and Politics in the Receiving States, International Migration Review 26, 1144-1167.

[27] Friebel G., Manchin M., Mendola M., Prarolo G. (2018), Human Smuggling and Intentions to Migrate: Global Evidence from a Supply Shock along Africa-to-Europe Migration Routes, Development Working Papers 432, Centro Studi Luca d'Agliano, University of Milano.

[28] Gagliarducci S., Nannicini T., Naticchioni P., (2011), Electoral Rules and Politicians' Behavior: a Micro Test, American Economic Journal: Economic Policy, 3(3), 144-174. 
[29] Glaeser E. L., Shleifer A., (2005), The Curley Effect: The Economics of Shaping the Electorate, The Journal of Law, Economics and Organization 21(1), 1-19.

[30] Gonzalez C., Conde-Ruiz J. I., Boldrin M. (2009) Immigration and Social Security in Spain, Fedea working paper n. 26.

[31] Grossman G. M., Helpman E., (2009), Party Discipline and Pork-Barrel Politics, in Helpman E. (ed.), Institutions and Economic Performance, Harvard University Press, Chapter 8, 329-360.

[32] Hanson G., Spilimbergo A. (2001), Political Economy, Sectoral Shocks, and Border Enforcement, Canadian Journal of Economics, 34(3), 612-638.

[33] Iversen T., Soskice D., (2006), Electoral Institutions and the Politics of Coalitions: Why Some Democracies Redistribute More than Others, American Political Science Review 100(2), 165-181.

[34] Jurado I., Leòn S., (2017), Geography Matters: The Conditional Effect of Electoral Systems on Social Spending, British Journal of Political Science 42(4), 855-877.

[35] Kaushal N., (2005) New Immigrants' Location Choices: Magnets Without Welfare, Journal of Labor Economics, 23 (1), 59-80.

[36] Keefer P., (2006) "Database of Political Institutions (DPI): Changes and Variables Definitions, Development Research Group, World Bank, Washington, DC.

[37] Key V. O., (1966) The Responsible Electorate: Rationality in Presidential Voting 1936-1960. Cambridge MA: Belknap Press.

[38] Kramer G. H. (1971) Short-Term Fluctuations in U.S. Voting Behavior: 1896-1964, American Political Science Review 65, 131-143.

[39] Lewis-Back M. S., (1988) Economics and Elections: The Major Western Democracies, Ann Arbor, MI: University of Michigan Press.

[40] Lizzeri A., Persico N. (2001) The Provision of Public Goods under Alternative Electoral Incentives, American Economic Review 91(1), 225-239.

[41] Markus G. (1988) The Impact of Personal and National Economic Conditions on the Presidential Vote: A Pooled Cross-Section Analysis, American Journal of Political Science 32, 137-154.

[42] Mayda A. M. (2006) Who is Against Immigration? A Cross-Country Analysis of Individual Attitudes towards Immigrants, The Review of Economics and Statistics 88(3), 510-530. 
[43] Mayda A.M., Facchini G. (2008), From Individual Attitudes towards Migrants to Migration Policy Outcomes: Theory and Evidence, Economic Policy 56, 651-713.

[44] Milesi-Ferretti G. M., Perotti R., Rostagno M., (2002) "Electoral Systems And Public Spending", The Quarterly Journal of Economics, MIT Press, vol. 117(2), pages 609-657, May.

[45] Morelli M., Negri M., (2017) Electoral Systems, Taxation and Immigration Policies: Which System Build a Wall First? CEPR Discussion Paper 12212.

[46] Nannestad P., 2007, Immigration and Welfare States: A Survey of 15 Years of Research, European Journal of Political Economy, 23, 512-532.

[47] O’ Rourke K. H., Sinnott R., (2006) The Determinants of Individual Attitudes towards Immigration, European Journal of Political Economy, 22, 838-861.

[48] Ottaviano G., Peri G., (2012), Rethinking the Effect of Immigration on Wages, Journal of the European Economic Association vol. 10(1), 152-197.

[49] Patty J. W., Weber R. (2007) Letting the Good Times Roll: A Theory of Voter Inference and Experimental Evidence, Public Choice 130, 293-310.

[50] Peri G., Yasenov V. (), The Labor Market Effects of a Refugee Wave: Applying the Synthetic Control Method to the Mariel Boatlift, NBER Working Papers 21801.

[51] Persson T., (2002) Do Political Institutions Shape Economic Policy? Econometrica 70(3), 883-905.

[52] Persson, T., Roland G., Tabellini G., (1997), Separation of Powers and Political Accountability, Quarterly Journal of Economics 112, 1163-1202.

[53] Persson T., Tabellini G., (2000), Political Economics: Explaining Economic Policy, The MIT Press: Cambridge (Mass.).

[54] Persson T., Tabellini G. (2002) Political Economics and Public Finance, in Auerbach A.J. and Feldstein M. (eds), Handbook of Public Economics, Elsevier Science, vol. 3, ch. 24, pp. 1551-1659.

[55] Persson T., Tabellini G., (2003), The Economic Effects of Constitutions, The MIT Press: Cambridge (Mass.).

[56] Persson T., Tabellini G., (2004), Constitutional Rules and Fiscal Policy Outcomes, American Economic Review, 94, (1),25-45.

[57] Razin A., Sadka E., Suwankiri B. (2011), Migration and the Welfare State: Political-Economy Based Policy Formation, MIT Press. 
[58] Razin A., Sadka E., Swagel P. L. (2002), Tax Burden and Migration: a Political Economy Theory and Evidence, Journal of Public Economics 85(2), 167-190.

[59] Russo G. (2011), Voting over Selective Immigration Policies with Immigration Aversion, Economics of Governance 12(4), 325-351.

[60] Russo G., Salsano F. (2012), Electoral Systems and Immigration, MPRA paper No. 38497.

[61] Sand E., Razin A. (2007) The Political Economy Positive Role of the Social Security System in Sustaining Immigration (but not Viceversa), NBER working paper n. 13598.

[62] Storesletten K., (2000), Sustaining Fiscal Policy through Immigration, Journal of Political Economy 108(2), pp. 300-323.

[63] Ticchi D., Vindigni A., (2009), Endogenous Constitutions, Economic Journal 120, 1-39.

[64] Wolfers J., (2013), Are Voters Rational? Evidence from Gubernatorial Elections, forthcoming, Review of Economics and Statistics. 


\section{Appendix}

Robustness checks of regression (21)

Our specification is necessarily basic; thus, we try to improve the analysis as much as possible by taking into account some omitted variables that might be correlated with both electoral systems and openness to immigration. Bertocchi and Strozzi $(2010,2008)$ argue that laws determining citizenship ${ }^{48}$ can affect openness to immigration in the long run. For example, jus soli legislation may cause restrictive immigration policies because it makes naturalization easier. In addition, ethnic and linguistic fragmentation can affect voting rules and favor proportional voting systems, which assure a better representation of minorities. Moreover, fragmentation increases public spending in order to secure the consensus of different groups (Alesina and Spolaore, 2003).

These issues are addressed by adding to our regressors dummy variables for jus soli and for ethnolinguistic fragmentation (we use the index developed by Alesina et al., 1999 $)^{49}$. The estimated coefficient for these variables is not significant, and the overall results of the regression are unchanged ${ }^{50}$.

We perform another check by controlling for the presence of outliers, which can be very important in small-sample analyses. When one country per time is excluded, the coefficients are unaffected. Finally we tried to account for other possible pull factors by including in the regressors the business freedom index provided by the Heritage Society (average 1996-2014). The coefficient was positive but not statistically significant.

\section{Proof of Lemma 1)}

Suppose the policymaker decides to use transfers, i. e., $f>0$. Since in equilibrium the budget constraint (8) holds, his rent (thus his expected utiltity) is decreasing in $\sigma$. As a consequence, he will set $\sigma$ to the minimum level that allows him to compensate enough decisive voters. When transfers are used, this level is $1 / 2$ under both electoral systems.

\section{Proof of Proposition 2)}

The policymaker wants to reduce expenditures as much as possible in order to maximize his rents, subject to the constraint of giving the decisive voters their reservation utility

$$
\bar{\omega}_{i j k}=(1-t)+\Psi_{i} f+h\left(g_{j k}, m\right)
$$

with $\Psi_{i}=1$ if and only if compensation occurs through transfers. Using total differentiation or the implicit function theorem, a change in $m$ must be compensated with a change in $f$ equal to

\footnotetext{
${ }^{48}$ Rules governing citizenship acquisition can be traced basically to jus soli and jus sanguinis. In the first case, citizenship is attributed according to birthplace. In the second case, children receive their parents' citizenship.

${ }^{49}$ This index of ethnolinguistic fractionalization measures the probability that two randomly selected people from a given country will not belong to the same ethnolinguistic group.

${ }^{50}$ These results are available upon request.
} 


$$
\frac{d f}{d m}=-h_{m}\left(g_{j k}, m\right)
$$

or with a change in $g_{j k}$ equal to

$$
\frac{d g_{j k}}{d m}=-\frac{h_{m}\left(g_{j k}, m\right)}{h_{g}\left(g_{j k}, m\right)} .
$$

Note that, since $h_{m}\left(g_{j k}, m\right)$ is negative, both compensations are positive. The policymaker must then choose whether compensating through $f$ or through $g_{j k}$. In the plurality system, there are $C / 2$ decisive districts to be compensated. Therefore, compensation through public goods entails the following marginal cost:

$$
M C C_{M g}=-\frac{h_{m}\left(g_{j k}, m\right)}{h_{g}\left(g_{j k}, m\right)}\left(\frac{C}{2}\right) .
$$

Let us now compute the marginal cost when the policymaker uses transfers. In this case, the transfer that offsets the individual loss $h_{m}\left(g_{j k}, m\right)$ must be provided to $1 / 2$ voters (see Lemma 1 ) and to $1 / 2$ immigrants. Thus, the marginal cost of compensating decisive voters is

$$
M C C_{M f}=-h_{m}\left(g_{j k}, m\right)\left(\frac{n+m}{2}\right) .
$$

Public goods are used when $M C C_{M g} \leq M C C_{M f}$, namely,

$$
-\frac{h_{m}\left(g_{j k}, m\right)}{h_{g}\left(g_{j k}, m\right)}\left(\frac{C}{2}\right) \leq-h_{m}\left(g_{j k}, m\right)\left(\frac{n+m}{2}\right) .
$$

Inequality (26) can be rearranged to

$$
h_{g}\left(g_{j k}, m\right)(n+m) \geq C .
$$

Consider now a proportional system. The policymaker still wants to keep the decisive voters on their reservation utility. Under proportional representation, there are $n / 2$ decisive voters. If he distributes compensation through $f$, the marginal cost of compensating $n / 2$ voters is still given by equation (25). On the other hand, if he uses $g_{j k}$ to satisfy $n / 2$ voters, he has to provide with public goods $C$ districts rather than $C / 2$. The marginal cost of compensation in this case is

$$
M C C_{P g}=-\frac{h_{m}\left(g_{j k}, m\right)}{h_{g}\left(g_{j k}, m\right)}(C) .
$$

Transfers are used if $M C C_{P f} \leq M C C_{P g}$, i. e.,

$$
-h_{m}\left(g_{j k}, m\right)\left(\frac{n+m}{2}\right) \leq-\frac{h_{m}\left(g_{j k}, m\right)}{h_{g}\left(g_{j k}, m\right)}(C) .
$$

Inequality (29) boils down to

$$
h_{g}\left(g_{j k}, m\right)(n+m) \leq 2 C .
$$


Inequalities (27) and (30) enable us to assess the bias electoral systems exert on public expenditure. To make it more evident, we simply rewrite inequality (30) to see when the policymaker uses public goods in the proportional system:

$$
h_{g}\left(g_{j k}, m\right)(n+m)>2 C .
$$

If we look at the equivalent condition for the plurality system, i.e. (27), it is clear that (31) is more restrictive. Thus, the often-found bias of plurality systems towards public goods and of proportional systems towards transfers also appears in our model ${ }^{51}$. However, this bias can be overcome by immigration. Actually, by conditions (27) and (30) we know that the policymaker uses public goods in the plurality system and transfers in the proportional system when

$$
C \leq h_{g}\left(g_{j k}, m\right)(n+m) \leq 2 C .
$$

In order to clarify what happens when condition (32) does not hold, we proceed as follows: we start from $m=0$; then, we let $m$ increase. When $m=0$, condition (32) reads

$$
C \leq h_{g}\left(g_{j k}, 0\right) n \leq 2 C .
$$

Suppose for simplicity that condition (33) holds. Thus, as the first immigrant enters the country, proportional systems compensate through transfers and plurality systems through public goods. What goes on as $m$ grows furhter? In this respect, note that, in condition (32), the term $(n+m)$ is increasing in $m$ and the term $h_{g}\left(g_{j k}, m\right)$ is decreasing in $m$ by assumption (4). Thus, the net effect is in principle undetermined.

Here, we make the following assumption: either $h_{g}\left(g_{j k}, m\right)$ weakly dominates $(n+m)$, or viceversa. As a consequence, the product $h_{g}\left(g_{j k}, m\right)(n+m)$ is weakly monotonic (either increasing or decreasing) in $m$. An example is visible in figure A.1, where condition (33) holds: when the product $h_{g}\left(g_{j k}, m\right)(n+m)$ is increasing in $m$, plurality systems always compensate with public goods. On the other hand, in proportional systems there exists a cutoff level of immigration above which they switch from transfers to public goods. When the product $h_{g}\left(g_{j k}, m\right)(n+m)$ is decreasing in $m$, proportional systems always use transfers, while for plurality systems it appears a cutoff level of immigration above which they switch to transfers.

In general, our weak monotonicity assumption is little restrictive and rules out multiple equilibria. It assures that, when condition (32) holds, proportional systems compensate through transfers and plurality systems through public goods. In any interval $h_{g}\left(g_{j k}, m\right)(n+m)<C$ both systems use transfers, and in any interval $h_{g}\left(g_{j k}, m\right)(n+m)>2 C$ both systems use public goods.

\section{Proof of Proposition 3}

Optimization requires that the policymaker equals the marginal benefit $t$ (namely, the tax base increase) to the marginal cost of compensation. From

\footnotetext{
${ }^{51}$ We acknowledge an anonymous reviewer who led us to rewrite our proofs in a more intuitive manner.
} 
Proposition 2, we know that there are three possible cases: 1) compensation of decisive voters occurs through transfers in both systems $\left[h_{g}\left(g_{j k}, m\right)(n+m)<C\right]$; 2) compensation of decisive voters occurs through public goods in both systems $\left.\left[h_{g}\left(g_{j k}, m\right)(n+m)>2 C\right] ; 3\right)$ compensation of decisive voters occurs through public goods in the plurality system and through transfers in the proportional system $\left[C \leq h_{g}\left(g_{j k}, m\right)(n+m) \leq 2 C\right]$.

In case 1$)$, the condition that defines the optimal level of $m$ is

$$
t=-h_{m}\left(g_{j k}, m\right)\left(\frac{n+m}{2}\right)
$$

in both electoral systems, thus they generate the same level of immigration.

In case 2 ), the optimality conditions imply that

$$
\underbrace{t=\frac{-h_{m}\left(g_{j k}, m^{*}\right)}{h_{g}\left(g_{j k}, m^{*}\right)}\left(\frac{C}{2}\right)}_{\text {plurality }}=\underbrace{\frac{-h_{m}\left(g_{j k}, m^{* *}\right)}{h_{g}\left(g_{j k}, m^{* *}\right)} C}_{\text {proportional }},
$$

therefore $m^{*} \neq m^{* *}$. Suppose $m^{*}>m^{* *}$. Then, for $m=m^{*}$ the marginal compensation cost should be higher in the proportional system, thus we can write the following inequality:

$$
\underbrace{\frac{-h_{m}\left(g_{j k}, m^{*}\right)}{h_{g}\left(g_{j k}, m^{*}\right)}(C)}_{\text {proportional }}>\underbrace{\frac{-h_{m}\left(g_{j k}, m^{*}\right)}{h_{g}\left(g_{j k}, m^{*}\right)}\left(\frac{C}{2}\right)}_{\text {plurality }}
$$

namely, $1>(1 / 2)$. This verifies that for $m=m^{*}$ the marginal compensation cost in the proportional system is higher than $t$, thus $m^{*}$ must be greater than $m^{* *}$ (recall also that the marginal compensation cost through public good is increasing in $m^{52}$ ).

Consider now case 3). Again, in equilibrium we have

$$
t=-h_{m}\left(g_{j k}, m^{* *}\right)\left(\frac{n+m^{* *}}{2}\right)=\frac{-h_{m}\left(g_{j k}, m^{*}\right)}{h_{g}\left(g_{j k}, m^{*}\right)}\left(\frac{C}{2}\right),
$$

therefore $m^{*} \neq m^{* *}$. Suppose $m^{*}>m^{* *}$. Then, as in case 2), for $m=m^{*}$ the marginal compensation cost should be higher in the proportional system. This implies

$$
\underbrace{-h_{m}\left(g_{j k}, m^{*}\right)\left(\frac{n+m^{*}}{2}\right)}_{\text {proportional }}>\underbrace{\frac{-h_{m}\left(g_{j k}, m^{*}\right)}{h_{g}\left(g_{j k}, m^{*}\right)}\left(\frac{C}{2}\right)}_{\text {plurality }},
$$

namely

$$
h_{g}\left(g_{j k}, m^{*}\right)\left(n+m^{*}\right)>C,
$$

which holds because condition (32) applies.

\footnotetext{
${ }^{52} \frac{d}{d m}\left(\frac{-h_{m}\left(g_{j k}, m\right)}{h_{g}\left(g_{j k}, m\right)}\right)=\frac{-h_{m m}\left(g_{j k}, m\right)}{h_{g}\left(g_{j k}, m\right)}+\frac{h_{g m}\left(g_{j k}, m\right) h_{m}\left(g_{j k}, m\right)}{\left[h_{g}\left(g_{j k}, m\right)\right]^{2}}>0$ by assumptions (3) and (4).
} 